\title{
NATIVOS DIGITAIS: CONSIDERAÇÕES SOBRE OS ALUNOS CONTEMPORÂNEOS E A POSSIBILIDADE DE SE (RE)PENSAR A PRÁTICA PEDAGÓGICA
}

\author{
DIGITAL NATIVES: CONSIDERATIONS ON CONTEMPORARY STUDENTS AND \\ THE POSSIBILITY OF IF (RE) THINKING PEDAGOGICAL PRACTICE
}

\author{
Thaís Cristina Rodrigues TEZANI ${ }^{1}$
}

RESUMO: Nosso objetivo nesse artigo é realizar uma discussão teórica e analisar alguns dados empíricos de uma pesquisa a qual relaciona os nativos digitais e a prática pedagógica em escolas dos anos iniciais do ensino fundamental mediada pelas Tecnologias Digitais da Informação e Comunicação (TDIC). Estudos apontam mudanças no processo educativo e nas interações sociais, mediadas pelas tecnologias, dos nativos digitais. Utilizamos apoio de estudos teóricos para fundamentar nossas discussões, apresentamos os dados coletados com os alunos dos anos iniciais do ensino fundamental, considerados nativos digitais e relacionamos sua análise com a possibilidade de se (re)pensar a prática pedagógica, uma vez que as TDIC estão presentes na vida social e na mediação da aprendizagem desses nativos digitais. A discussão sobre essas temáticas é fundamental para compreendermos a atual conjuntura do processo de ensinar e aprender contemporâneo.

PALAVRAS-CHAVE: Nativos digitais. Prática pedagógica. Tecnologias digitais da informação e comunicação. Educação.

ABSTRACT: Our goal in this article is to performatheoretical discussion and review some empirical data of a survey which lists the digital natives and the pedagogical practice in schools in the early years of elementary school mediated by digital technologies of information and communication (TDIC). Studies indicate changes in the educational processand in social interactions, mediated by technologies of digital natives. We use support from theoretical studies to substantiate our discussions, we present the datacollectedwiththe students of the early years of elementary school, considered to be digital natives and relate its analysis with the possibility to (re) thinking the pedagogical practice, once the TDIC are present in social life and in the mediation of learning of these digital natives. The discussion on these themes is essential to understand the current situation of the teaching and learning process.

KEYWORDS: Digital natives. Pedagogical practice. Digital technologies of information and communication. Education.

1 Universidade Estadual Paulista (Unesp), Faculdade de Ciências, Bauru - SP - Brasil. Professora do Departamento de Educação. E-mail: thaistezani @yahoo.com.br. 


\section{Introdução}

As tecnologias estão presentes em todos os momentos da nossa vida, isso envolve desde o uso social que resulta da interação entre o homem e as máquinas até as práticas advindas das transformações sobre esses equipamentos que acontecem por meio da socialização humana.

Inicialmente denominadas como Tecnologias da Informação e Comunicação (TIC) que englobavam a televisão, o rádio e o jornal, e hoje sendo conhecidas como Tecnologias Digitais da Informação e Comunicação (TDIC), pois abrangem dispositivos eletrônicos que se utilizam da internet como computadores, tablets e smartphones, é que nos basearemos para as considerações desse texto. Para Kenski (2010, p. 133) “[...] a convergência das tecnologias de informação e comunicação para a configuração de uma nova tecnologia, a digital, provocou mudanças radicais."

Assim, terminologia TDIC é a mais adequada para o momento, pois vivemos num contexto repleto de dispositivos móveis que permitem a navegação pela internet e o acesso ao ciberespaço. As mudanças advindas dessas tecnologias nos processos de ensino e aprendizagem possibilitaram que vários pesquisadores se interessassem pela temática e realizassem estudos na área, como Kenski (2010, 2003, 1998); Almeida e Prado (2006); Barros (2009); Belloni (2010); Buckinham (2010); Rossato (2014); Silva (2006); Valente (2003).

Grande parte desses estudos questiona a facilidade de acesso à informação e como isso está sendo trabalhado na prática pedagógica. Indagam ainda sobre novas possibilidades de ensinar e aprender uma vez que os alunos contemporâneos são também conhecidos como nativos digitais. Afirmam que as TDIC transformaram as interações sociais e o acesso à informação fora dos muros das escolas, porém apresentaram também considerações relevantes sobre novas formas de ensinar e aprender que estão surgindo por meio da interação entre o real e o virtual.

Nossos alunos estão imersos num contexto digital. Inseridos em uma sociedade digitalizada na qual as TDIC estão presentes na organização e no funcionamento da vida cotidiana, indagamos sobre seu uso no processo de ensino e aprendizagem: Como (re)pensar a prática pedagógica diante das especificidades dos nativos digitais?

Destacamos que há ainda um abismo no que tange o uso das TDIC na vida social e na educação escolar: fora da escola nossos alunos utilizam esse universo tecnológico, porém ainda encontramos restrições desse uso na prática pedagógica, o que foi comprovado pelos dados coletados, apresentados e analisados nesse artigo. 
Para Buckingham (2010) tal situação advém de vivenciarmos na escola contemporânea práticas nas quais a tecnologia digital não utilizada, enquanto fora dos muros escolares os alunos vivem num universo de exacerbação midiática.

As TDIC são por nós, consideradas como instrumentos mediadores, pois a aprendizagem e o ensino são formas universais de desenvolvimento mental. O ensino propicia a apropriação da cultura e o desenvolvimento do pensamento, dois processos articulados entre si, formando uma unidade. Podemos expressar essa ideia de duas maneiras: a) enquanto o aluno forma conceitos científicos, incorpora processos de pensamento e vice-versa; b) enquanto forma o pensamento teórico, desenvolve ações mentais, mediante a solução de problemas que suscitam a atividade mental do aluno. Com isso, o aluno assimila o conhecimento teórico e as capacidades e habilidades relacionadas a esse conhecimento, mediado pelas TDIC (VYGOTSKY, 1998, 1996).

Sendo assim, nosso objetivo nesse artigo é realizar uma discussão teórica e analisar alguns dados empíricos de uma pesquisa com alunos sobre os nativos digitais e a prática pedagógica em escolas dos anos iniciais do ensino fundamental mediada pelas Tecnologias Digitais da Informação e Comunicação (TDIC). Para isso, apresentamos algumas características dos alunos atuais também conhecidos como nativos digitais; a pesquisa: seu instrumento, resultados e análises; a possibilidade de se (re)pensar a prática pedagógica.

Acreditamos que estudos dessa natureza contribuem para discussões fundamentais relacionadas à prática pedagógica diante das possibilidades de uso das TDIC no processo de ensino e aprendizagem de modo racional, crítico e consciente.

\section{Quem são os nativos digitais?}

Nossos alunos mudaram radicalmente. Os alunos de hoje não são os mesmos para os quais nosso sistema educacional foi criado. (PRESNSKY, 2001, p. $1)$.

Estudos realizados por Presnsky (2001) e Palfrey e Gasser (2011) apontam mudanças de comportamento dos alunos, articuladas também a mudanças de valores e atitudes sociais. Para esses estudiosos os denominados "nativos digitais" caracterizam-se pelo uso constante das TDIC por meio de dispositivos móveis.

Para Presnsky (2001, p. 1) esses alunos caracterizam-se por nascerem a partir de 1990 e por estarem rodeados pelas TDIC. O universo digital é delas parte integrante de suas vidas, 
sendo assim, “[...] o grande volume de interação com a tecnologia, os alunos de hoje pensam e processam as informações bem diferentes das gerações anteriores."

Nos estudos de Palfrey e Gasser (2011, p. 13) os nativos digitais são aqueles que possuem habilidades com as TDIC em vários contextos como nos relacionamentos (redes sociais), busca de informações, novas formas de comunicação, possibilidade de aprender. Podemos afirmar, portanto, que "[...] o mais incrível, no entanto, é a maneira em que a era digital transformou o modo como as pessoas vivem e se relacionam umas com as outras e com o mundo que as cerca."

Os nativos digitais, segundo Franco (2013), apresentam familiaridade com o uso de computadores, games e vídeo games conectado ao ciberespaço. É nesse contexto também que ocorrem os relacionamentos sociais, pois por meio das redes sociais compartilham como o mundo suas ideias, fotos, vídeos, com pessoas que fazem parte do seu convívio social real e até com pessoas que apenas mantém contato virtualmente. São capazes de pesquisar informações e processar o recebimento de tudo isso com rapidez, realizam inúmeras atividades ao mesmo tempo.

“Os nativos digitais estão acostumados a receber informações muito rapidamente. Eles gostam de processar mais de uma coisa por vez e realizar múltiplas tarefas." (PRESNSKY, 2001, p. 2).

Para Presnsky (2001) os que não nasceram o mundo digital, mas que vivem com as TDIC e que adotam posturas de abertura para as possibilidades do ciberespaço são considerados imigrantes digitais. Assim, podemos considerar que os nativos digitais são aqueles que "[...] nasceram e cresceram na era da tecnologia digital, enquanto os imigrantes digitais nasceram na era analógica, tendo migrado posteriormente para o mundo digital." (MATTAR, 2014, p.4).

Como consequência disso, nativos e imigrantes digitais pensariam e processariam informações de formas diferentes, assim "[...] o único e maior problema que a educação enfrenta hoje é que os nossos instrutores Imigrantes Digitais, que usam uma linguagem ultrapassada (da era pré-digital), estão lutando para ensinar uma população que fala uma linguagem totalmente nova." (PRESNKY, 2001, p. 2).

Com base nesse estudo publicado, elaboramos o seguinte quadro comparativo. 
Quadro 1: Imigrantes Digitais x Nativos Digitais

\begin{tabular}{|c|c|}
\hline Imigrantes Digitais & Nativos Digitais \\
\hline - Livros & - TV, Internet e games \\
\hline - Textual & - Visual \\
\hline - Sotaque & - Falantes nativos \\
\hline - Raciocínio lento & - Raciocínio rápido \\
\hline - Método & - Tentativa e erro \\
\hline - Ordem & - Acesso randômico \\
\hline - Uma coisa por vez & - Multitarefas \\
\hline - Teoria & - Prática \\
\hline - Aprendizado individual & - Aprendizado colaborativo \\
\hline
\end{tabular}

Fonte: Elaboração própria com base em Presnky (2001); Palfrey e Gasser (2011)

Em estudo posterior, Prensky (2012) revisa o conceito de nativos digitais e passa a usar a terminologia sabedoria digital, a qual não exploraremos nesse momento.

Por outro lado, e em contraposição a essas ideias, Koutropoulos (2011) considera que a existência dessa nova geração também conhecida como digital e os aspectos que envolvem seu processo de ensino e aprendizagem ainda são baseados no senso comum, pois ainda há existência de estudos científicos pautados em pesquisas empíricas sobre o assunto. O que ocorre é as características apontadas não revelam aspectos como definição específica da faixa etária, localização geográfica, situação socioeconômica, entre outros.

Porém, não como negar que o acesso da população às TDIC aumentou nos últimos anos em virtude da facilidade na aquisição e no manuseio dos smartphones. Com base nos dados o IBGE (Instituto Brasileiro de Geografia e Estatística) de 2010, tínhamos 1,4 aparelhos de celular por habitante. Tais dados nos leva a afirmar que mesmo que alguns brasileiros não tenham um smartphone as TDIC estão cada vez mais presentes nas nossas vidas (KENSKI, 2003).

Portanto, consideramos fundamental discutir com os alunos, nativos digitais, dos anos iniciais do ensino fundamental sobre o uso das TDIC nas relações sociais e no processo de ensinar e aprender.

\section{O que dizem os nativos digitais?}


De fato, mais do que a mera aquisição de saberes, a sociedade em que hoje vivemos exige de cada cidadão o desenvolvimento de um conjunto de competências essenciais, nomeadamente a de adaptação à mudança, sendo isso particularmente relevante para todos os que desempenham já uma atividade profissional concreta, qualquer que ela seja. (COSTA; FRADÃO, 2012, p. 27).

Durante as atividades da disciplina "Recursos Tecnológicos Aplicados à Educação" do curso de Pedagogia da UNESP da Bauru SP, no ano de 2015, realizamos uma atividade de natureza teórico-prática com alunos dos anos iniciais do ensino fundamental. Foi preservado o anonimato dos sujeitos e para participarem seus pais tiveram que assinar Termo de Assentimento Livre e Esclarecido, assim como os diretores das Unidades Escolares que assinaram Termo de Consentimento Livre e Esclarecido.

Foram entrevistados 45 alunos, consideramos nativos digitais, pelos alunos do curso. Essas entrevistas seguiram um roteiro e foram realizadas em contextos distintos: escolas públicas e particulares de Bauru SP. Sabemos que tal público não reflete a totalidade dos alunos e por isso não nos cabe realizar generalizações apenas tecer algumas considerações.

O roteiro foi subdivido em seções: identificação, escola, televisão, computador, celular. E, possuía 20 questões, sendo que destas 14 eram de múltipla escola e 6 com possibilidade de respostas abertas.

Apresentaremos os dados conforme as seções do instrumento, dividindo assim as informações coletadas.

No primeiro item "Identificação"forampesquisados os seguintes aspectos: idade, ano, escola (particular, municipal, estadual). O Gráfico1 apresenta os dados relacionados entre idade, ano e escola.

Gráfico 1: Idade, ano e escola

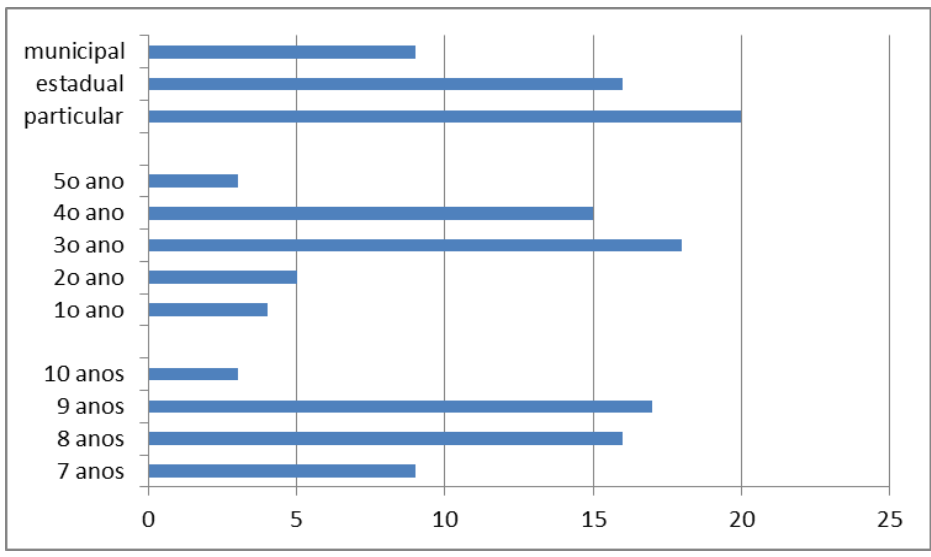

Fonte: Dados da pesquisa. 
Conforme apresentado no Gráfico 1 tivemos 8,9\% dos entrevistados com 7 anos e cursando o $1^{\circ}$ ano; 11,1 com 8 anos cursando o $2^{\circ}$ ano; $40 \%$ com 9 anos cursando o $3^{\circ}$ ano; $33,3 \%$ com 10 anos cursando o $4^{\circ}$ ano e $6,7 \%$ com 11 anos cursando o $5^{\circ}$ ano. Cabe destacar que as entrevistas foram realizadas no segundo semestre de 2015. Com relação à escola, 20\% frequentavam escolas particulares; $35,6 \%$ escolas municipais e 44,4\% escolas estaduais.

No segundo item "Escola" foram pesquisados os seguintes aspectos: os recursos usados pelo professor da sua turma durante as aulas;os recursos que possibilitam aprender melhor; o que gostaria que fosse usado pelo professor em sala de aula. Para essas questões o aluno poderia escolher mais de uma alternativa.

Ficou evidente que a lousa era o recurso didático mais usado pelos professores na prática pedagógica. Para Barros (2009, p. 62), o uso das tecnologias no processo de ensino e aprendizagem é considerado complexo e exige dos professores habilidades e competências diferenciadas. "Além de competências técnicas, exige também as competências pedagógicas, as mais importantes para a gestão das tecnologias para o ensino." Costa e Fradão (2012) verificam a ausência das tecnologias na formação inicial de professores o que resulta na sua ausência também na prática pedagógica.

Para a questão seguinte, 93,3\% os alunos afirmaram que aprendem melhor com a lousa e o livro didático, isso porque esses são os recursos mais usados pelos professores.

Entretanto, $100 \%$ dos entrevistados gostariam que o professor usasse mais o computador/notebook/netbook em suas aulas, desses $84,4 \%$ solicitaram também o uso da lousa digital.

Nessa mesma direção, Valente (2003) afirma que há necessidade de integrar a informática nas atividades pedagógicas e, portanto na prática docente. Esse processo articula o saber e prática docente ao uso das tecnologias, sendo essencial em virtude das necessidades da sociedade contemporânea.

No terceiro item "Televisão" foram pesquisados os seguintes aspectos: programas que gosta de assistir; tempo que fica em frente à televisão por dia; se já pediu para um adulto comprar produtos que passam na televisão e quais foram. Agrupamos as respostas das duas primeiras questões no Gráfico 2. 
Gráfico 2: Programas que gosta de assistir e horas em frente à televisão por dia

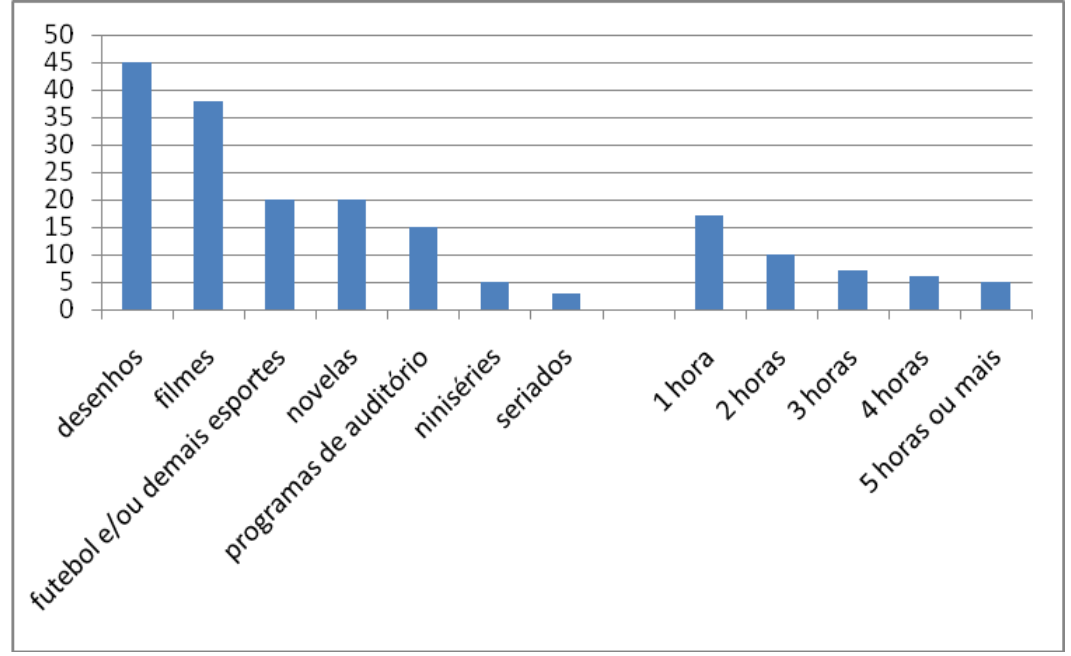

Fonte: Dados da pesquisa.

Conforme apresentado no Gráfico 2, 100\% dos sujeitos assistem desenhos, seguido de filmes, esportes, novelas, programas de auditório, minisséries e seriados. Cabe destacar que mais uma resposta poderia ser escolhida pelos entrevistados.

Com relação ao número de horas em frente à televisão durante um dia, 37,9 afirmaram ficar apenas 1 hora, seguido de 22,2\% (2 horas), 15,5\% (3 horas), 13,3\% (4 horas) e 11,1\% (5 horas ou mais).

Com relação a solicitação de compra de produtos que passam na televisão, $100 \%$ já solicitaram a compra de brinquedos, jogos para vídeo game, comidas, roupas e sapatos, o que nos reporta ao estudo de Belloni (2010).

No quarto item "Computador" foram pesquisados os seguintes aspectos: se tem computador; com acesso a internet e onde (casa ou escola); os sites que costuma acessar; como gostaria que fosse usado pelo seu professor na sala de aula.

Sobre possuir ou não computador, 95,6\% dos alunos disseram ter computador em casa com acesso à internet. Sobre os sites que costumam acessar, encontramos grande variedade: jogos online, redes sociais, vídeos, entre outros. E, como o gostaria que o computador fosse usado pelo professor em sala de aula, 93,3\% dos alunos sugeriram que fosse usado para pesquisa, já 6,7\% sugeriram que gostaria de explorar jogosonlinecom seus colegas de escola.

Diante dessas informações, nos apoiamos na afirmação de Kenski (2010, p. 18), pois “[...] este é também o duplo desafio para a educação: adaptar-se aos avanços das tecnologias e orientar o caminho de todos para o domínio e a apropriação crítica desses novos meios."

No quinto item "Celular" foram pesquisados os seguintes aspectos: se tem celular; com acesso a internet; se faz ligações e envia mensagens; se na sua escola o celular pode ser usado; 
como você gostaria que fosse usado pelo seu professor na sala de aula. Agrupamos algumas dessas respostas no Gráfico 3.

\section{Gráfico 3: Celular}

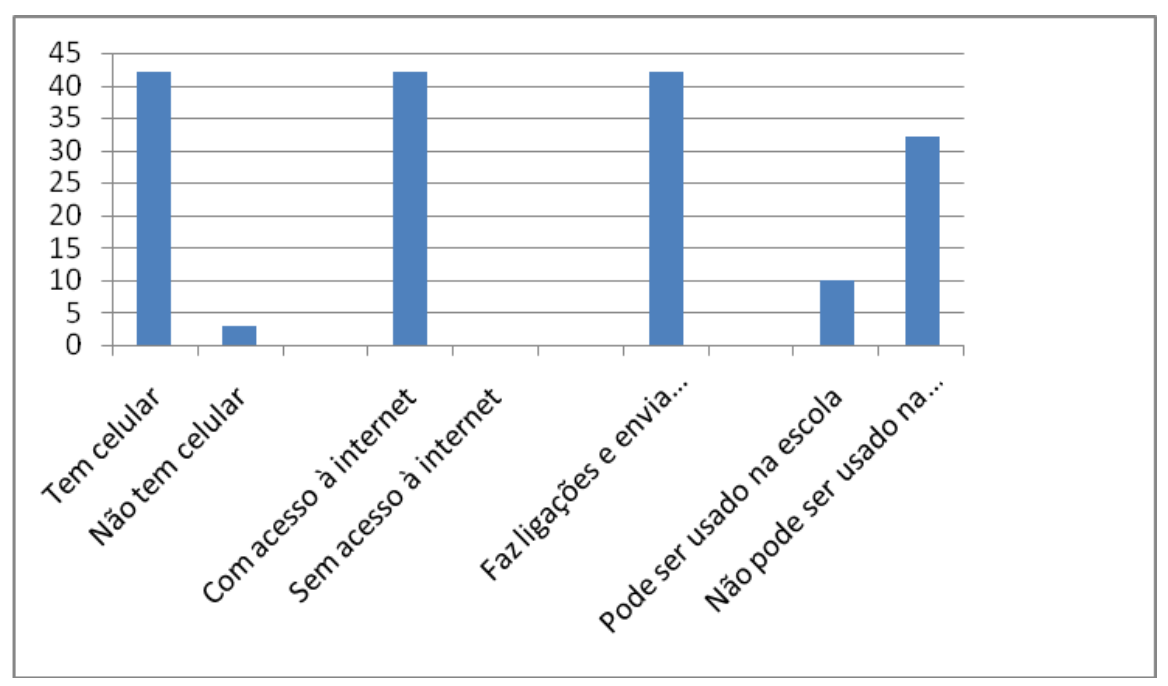

Fonte: Dados da pesquisa.

Ficou evidente pelos dados que os alunos que possuem celulares têm acesso à internet, fazem ligações e enviam mensagens. Entretanto, na escola seu uso ainda é restrito. Vários responderam que pode ser usado na escola, mas somente durante o recreio. Não havendo, portanto, a exploração dessa tecnologia no processo de ensino e aprendizagem. Para Kenski (2010, p.18) “[...] a educação também é um mecanismo poderoso de articulação das relações de poder, conhecimento e tecnologias."

Os alunos também não conseguem identificar essa tecnologia como m-learnig, ou seja, uma tecnologia móvel que pode ser usada para ensinar e aprender. Nas repostas sobre como gostaria que fosse usado pelo professor na sala de aula, os alunos indicaram que gostaria que fosse permitido o uso para ouvirem músicas.

\section{(Re)pensar a prática pedagógica}

$\mathrm{Na}$ cibercultura, os atores da comunicação tendem à interatividade e não mais à separação da emissão e recepção própria da mídia unidirecional de massa. Para posicionar-se nesse contexto e aí educar, os professores precisarão operar com o hipertexto, isto é, trabalhar com o contexto não-sequencial, com a montagem de conexões em rede, o que permite uma multiplicidade de recorrências entendidas como conectividade, diálogo e participação colaborativa. (SILVA, 2006, p. 17). 
O processo de ensinar e aprender dos nativos digitais, mediado pelas TDIC ainda é insipiente em algumas das escolas, como no caso das pesquisadas, segundo o entendimento dos alunos. Assim, nos cabe indagar que esse assunto precisa ser discutido nas escolas com os professores, ou seja, a utilização das TDIC como instrumentos mediadores da aprendizagem e, assim possibilitar (re)pensar a prática pedagógica.

Tal possibilidade de discussão da temática contribui para compreensão de que as mudanças nas interações sociais da sociedade contemporânea alterou também o processo de ensinar e aprender: os nativos digitais esperam mudanças, segundo os dados coletados. Assim, questionamos: qual é o papel da escola diante desse contexto?

Nas palavras de Almeida e Prado (2006, p. 51):

Com a integração das tecnologias e mídias na prática pedagógica se evidencia a importância de o professor compreender os processos de gestão da sala de aula, no que se refere ao ensino, à aprendizagem e às estratégias que desenvolve, na criação de situações que favoreçam ao aluno integrar significativamente os recursos das tecnologias e mídias, como forma de trabalhar a busca de informação, a pesquisa, o registro, as novas linguagens de expressão do pensamento, comunicação e produção do conhecimento.

Segundo Rossato (2014) grande parte da população ainda não tem acesso às TDIC e que tal situação provoca a exclusão digital. Diante dessa afirmação, consideramos que a escola é o espaço no qual o aluno tem o direito a ter acesso a esses recursos já que socialmente são usados.

A prática pedagógica, segundo Vilarinho (1984), está embasada em alguns princípios:

a) o objetivo básico do ensino é o domínio do conteúdo de estudo;

b) o ensino é sinônimo de transmissão de conhecimentos;

c) o professor é o elementomais importante do processo, pois representa a autoridade máxima, que detém osaber e o poder de avaliar o aluno;

d) o aluno recebe e reproduz o conhecimentotransmitido;

e) o conteúdo de aprendizagem é um fim em si mesmo, sendo organizadosegundo a lógica do professor para ser memorizada pelo aluno;

f) o método dadocência é a exposição oral, ou seja, tem cunho verbalista, transmissivo e se projetapara a dimensão intelectual do aprendiz;

g) as orientações da aprendizagem sãocoletivas, desconsiderando-se as diferenças individuais. 
Sendo assim, acreditamos que as TDIC têm exercido a função de instrumentos mediadores ao processo de ensinar e aprender dos nativos digitais, mesmo que de forma ainda insipiente em alguns contextos. Possibilitar ao nativo digital o acesso ao universo do ciberespaço e assim contribuir para o prazer da descoberta, da investigação, da curiosidade e da construção de novos conhecimentos, é que nos faz (re)pensar as práticas pedagógicas mediadas pelas TDIC.

Retomamos nosso objetivo com esse texto: realizar uma discussão teórica e analisar alguns dados empíricos de uma pesquisa a qual relaciona os nativos digitais e a prática pedagógica em escolas dos anos iniciais do ensino fundamental mediada pelas Tecnologias Digitais da Informação e Comunicação (TDIC). Desta forma, acreditamos que a educação escolar necessita rever seu papel diante das TDIC como instrumentos culturais da sociedade contemporânea, utilizando-as de modo crítico e consciente, de modo que as TDIC não sejam concebidas como salvadoras das mazelas da educação, mas como possibilidade de contribuir para o ensinar e o aprender.

\section{REFERÊNCIAS}

ALMEIDA, M. E. B. de; PRADO, M. E. B. Importância da gestão nos projetos de EaD. In: BRASIL. Secretaria de Educação a Distância. Debates: mídias na educação. Brasília, nov./dez. 2006. p.49-57. (Cadernos "Salto para o Futuro". Boletim, n.24).

BARROS, D. M. V. Guia didático sobre as tecnologias da comunicação e informação: material para o trabalho educativo na formação docente. Rio de Janeiro: Vieira \& Lent, 2009.

BELLONI, M. L. Crianças e mídias no Brasil: cenários de mudança. Campinas: Papirus, 2010.

BUCKINGHAM, D. Cultura digital, educação midiática e o lugar da escolarização. Educação e Realidade, Porto Alegre, v.35, n.3, p.37-58, 2010. Disponível em: <http://seer.ufrgs.br/educacaoerealidade/article/view/13077>. Acesso em: 22 nov. 2017.

COSTA, F. A.; FRADÃO, S. Desafios e competências do e-formador. In: BUTTENTUIT JÚNIOR, J. B.; COUTINHO, C. P. (Org.). Educação online: conceitos, metodologias, ferramentas e aplicações. Curitiba: CRV, 2012. p.27-39.

FRANCO, C. de P. Understanding digital natives learning experiences. Revista Brasileira de Linguística Aplicada, Belo Horizonte, v.13, n.3, p.643-658, 2013. Disponível em: <http://www.scielo.br/scielo.php?script=sci_arttext\&pid=S1984-63982013000200013>. Acesso em: 09 maio 2016.

KENSKI, V. M. Educação e tecnologias: o novo ritmo da informação. Campinas: Papirus, 2010. 
KENSKI, V. M. Tecnologia e ensino presenciale à distância. São Paulo: Papirus, 2003.

KENSKI, V. M. Novas tecnologias: o redimensionamentodo espaço e do tempo e os impactos no trabalho docente. Revista Brasileira de Educação, Rio de Janeiro, n.8, p.58-71, 1998. Disponível em:

$<$ http://pitagoras.unicamp.br/ teleduc/cursos/diretorio/tmp/1808/portfolio/item/61/Impactonot rabalhodocente_kenski.pdf $>$. Acesso em: 22 nov. 2016.

KOUTROPOULOS, A. Digital natives: ten years after. Journal of Online Teaching and Learning, [S.1.], v.7, n.4, 2011. Disponível em:

<http://jolt.merlot.org/vol7no4/koutropoulos_1211.htm>. Acesso em: 22 nov. 2016.

MATTAR, J. Games em Educação: apostila para o curso de Pós-Graduação em Inovação e Gestão em EaD pela USP. São Paulo: USP, 2014. Não publicado.

PALFREY, J.; GASSER, U. Nascidos na era digital: entendendo a primeira geração dos nativos digitais. Porto Alegre: ARTMED, 2011.

PRENSKY, M. From digital nativesto digital wisdom: hopefulessays for 21 st Century learning. Thousand Oaks: Corwin, 2012.

PRENSKY, M. Aprendizagem baseada em jogos digitais. São Paulo: Senac, 2001.

ROSSATO, M. A aprendizagem dos nativos digitais. In: MARTİNEZ, A.; ÁLVAREZ, P. (Org.). O sujeito que aprende: diálogo entre a psicanálise e o enfoque histórico-cultural. Brasília: Liber Livro, 2014. p.151-178.

SILVA, M. A pesquisa e a cibercultura como fundamentos para a docência online. In: BRASIL. Secretaria de Educação a Distância. Debates: mídias na educação. Brasília, nov./dez. 2006. p.17-23. (Cadernos "Salto para o Futuro". Boletim, n.24).

VALENTE, J. A. (Org.). Formação de educadores para o uso da informática na escola. Campinas: UNICAMP, 2003. Disponível em: 〈http://www.nied.unicamp.br/oea/pub/livro4/>. Acesso em: 22 nov. 2017.

VILARINHO, L. R. G. Didática: temas selecionados. Rio de Janeiro: Livros Técnicos e Científicos, 1984.

VYGOTSKY, L. S. Pensamento e Linguagem. Rio de Janeiro: Martins Fontes, 1998.

VYGOTSKY, L. S. A formação social da mente. Rio de Janeiro: Martins Fontes, 1996. 


\section{Como referenciar este artigo}

TEZANI, Thaís Cristina Rodrigues. Nativos digitais: considerações sobre os alunos contemporâneos e a possibilidade de se (re)pensar a prática pedagógica. Doxa: Rev. Bras. Psicol. Educ., Araraquara, v.19, n.2, p. 295-307, jul./dez. 2017. e-ISSN: 2594-8385.

Submetido em: 09/04/2017

Aprovado em: 18/06/2017 